\title{
Chapter 13 \\ The Linear Rise in the Number of Our Days
}

\author{
Jim Oeppen and James W. Vaupel
}

If life expectancy ${ }^{1}$ - also known as the expectation of life, is the mean life-span of a cohort of newborns if current age-specific death rates remain unchanged - in developed countries were close to an ultimate limit, then increases in record life expectancy - the average length of life in the best-practice population - should slow as the ceiling is asymptotically approached.

Best-practice national life expectancy has, contrary to what many believe ${ }^{2}$ (Olhansky et al. 2001; Riley 2001; Dublin 1928; Dublin and Lotka 1936; Olshansky

We are grateful to the many people who have provided comments and information, including Kenneth Wachter and Yasuhik Saito. A version of this article that does not include some of the material here but that includes some additional material was published by Oeppen and Vaupel in 2002.

${ }^{1}$ Most of the life-expectancy calculations in this article are based on data on death rates over age and time in the Human Mortality Database, see http://www.demog.berkeley.edu/wilmoth/mortality. Recent Japanese data can be found at http://www.mhlw.go.jp/english/database/index.html. Some data for the period before 1950 are from Keyfitz and Flieger (1968) and other sources.

${ }^{2}$ For reviews, see Preston (1974); Keilman (1997). For a critical account of the low mortality assumptions used by the U.S. Social Security Administration, see Lee (2000). A review of mortality forecasting in 13 European Union countries in the early- and mid-1990s found that all assumed that mortality improvements would decelerate and 10 constrained life expectancy to reach an ultimate limit by a target date (Cruijsen and Eding 2001). In a report notorious for missing the baby boom, Whelpton et al. (1947) focused their discussion on life-expectancy limits for U.S. native white males. They concluded that for this population a life expectancy in the year 2000 of 72.1 years was the upper limit of what could be achieved by the largest mortality "declines that seem reasonable" and close to what could be attained at the "biological minimum of mortality". In two publications Frejka $(1973,1981)$ focus on population growth rather than life expectancy. In the first, Frejka writes that "within broad limits mortality can be fairly well predicted." He believes that life expectancy will approach a limit and that 77.5 is the most likely limit. He notes, however, that "mortality might even take a course absolutely different from what has been assumed."

J. Oeppen $(\varangle) \cdot$ J. W. Vaupel

Max Planck Institute for Demographic Research, Rostock, Germany

e-mail: joeppen@health.sdu.dk

T. Bengtsson, N. Keilman (eds.), Old and New Perspectives on Mortality

Forecasting, Demographic Research Monographs,

https://doi.org/10.1007/978-3-030-05075-7_13 


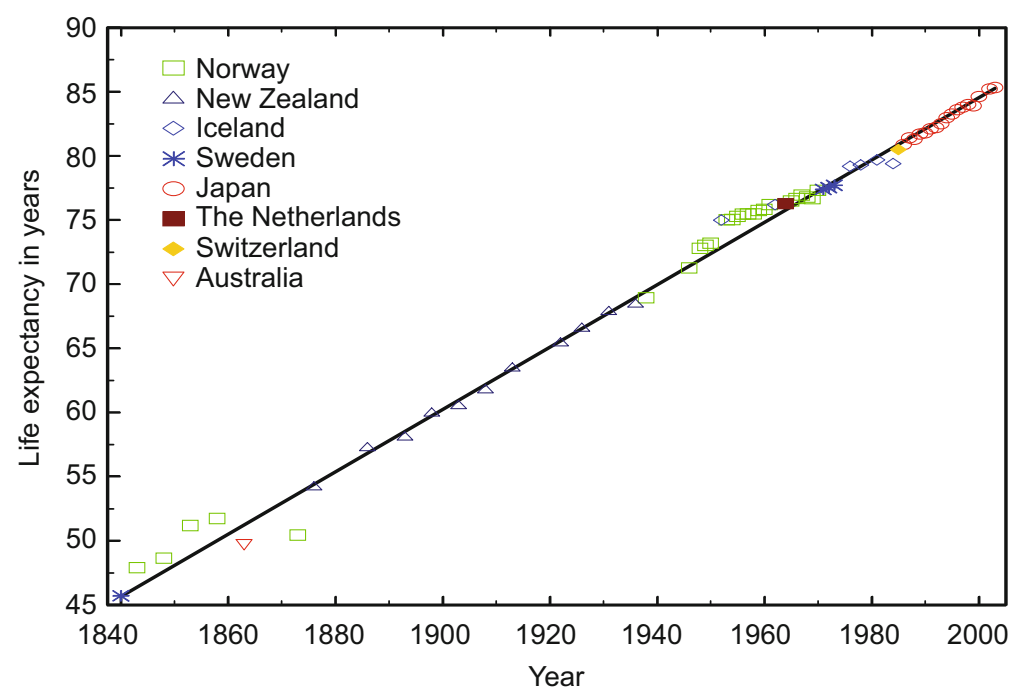

Fig. 13.1 Best-practice national life expectancy over the last 160 years

et al. 1990; Bourgeois-Pichat 1952, 1978; Fries 1980, 1990; Siegel 1980; Demeny 1984; United Nations 1973, 1985, 1989, 1999, 2001; NIPSSR 1997), risen for 160 years at a steady pace of 3 months per year as shown in Fig. 13.1.

Before 1950 most of the gain in life expectancy was due to large reductions in death rates at younger ages. The conventional view is that "future gains in life expectancy cannot possibly match those of the past, because they were achieved primarily by saving the lives of infants and children - something that happens only once for a population" (Olshansky et al. 2001). The sustained improvement in bestpractice life expectancy belies this contention. In the second half of the twentieth century improvements in survival after age 65 propelled the rise in the length of people's lives. For Japanese females, remaining life expectancy at age 65 grew from 13 years in 1950 to 22 years today, and the chance of surviving from 65 to 100 soared from less than 1 in 1000 to 1 in $20 .^{3}$

The linear climb of record life expectancy suggests that reductions in mortality should not be seen as a disconnected sequence of unrepeatable revolutions but rather as a regular stream of continuing progress. Mortality improvements result from the intricate interplay of advances in income, salubrity, nutrition, education, sanitation, and medicine, with the mix varying over age, period, cohort, place and disease (Riley 2001). Reinforcing processes may help sustain the increase. For instance, reductions in premature deaths reduce bereavement, an important risk factor for mortality. The improvements also increase the number of people who survive to high ages, leading to greater attention to health at those ages. Increasingly prosperous, educated populations aided by armies of researchers, physicians, nurses and public-

\footnotetext{
${ }^{3}$ Recent Japanese data can be found at http://www.mhlw.go.jp/english/database/index.html
} 
health workers incessantly seize opportunities to push death back. The details are complicated but the resultant - the straight line of life-expectancy increase - is simple.

For the world as a whole life expectancy has more than doubled over the past two centuries, from about 25 years to about 65 for men and 70 for women (Riley 2001). This transformation of the duration of life has greatly enhanced the quantity and quality of people's lives. It has fueled enormous increases in economic output and in population size, including an explosion in the number of the elderly (Fogel and Costa 1997; Martin and Preston 1994).

\subsection{Better Forecasts}

Although students of mortality eventually recognized the reality of improvements in survival, they blindly clung to the ancient notion that under favorable conditions the typical human has a characteristic lifespan, the Biblical three score and ten. As the expectation of life rose higher and higher, most experts were unable to imagine it rising much further. They envisioned various biological barriers and practical impediments. The notion of a fixed lifespan evolved into a belief in a looming limit to life expectancy.

Continuing belief in imminent limits is distorting public and private decisionmaking. Forecasts of the expectation of life are used to determine future pension, health-care and other social needs. Increases in life expectancy of a few years can produce large changes in the numbers of the old and very old, substantially augmenting these needs. The officials responsible for making projections - at the United Nations, the World Bank, and various national bureaus - recalcitrantly insist that life expectancy will increase slowly and not much further. The official forecasts distort people's decisions about how much to save and when to retire. They give politicians license to postpone painful adjustments to social-security and medicalcare systems (Vaupel 2000).

Officials charged with forecasting trends in life expectancy over future decades should base their calculations on the empirical record of mortality improvements over a corresponding or even longer span of the past ${ }^{4}$ (Lee and Carter 1992; Alho 1998; Tuljapurkar et al. 2000; Wilmoth 1998; Olshansky et al. 2001; Lee 2001). Because best-practice life expectancy has increased linearly by two and a half years per decade for a century and a half, one reasonable scenario would be that this trend will continue in coming decades. If so, record life expectancy will reach 100 in about six decades. This is far from immortality: modest annual increments in life

\footnotetext{
${ }^{4}$ Olshansky et al. (2001) use changes in age-specific probabilities of death over the decade from 1985 to 1995 to make long-term projections, one out to the year 2577. It is more appropriate to base long-term projections on long-term historical data and to use changes in central death rates. See Wilmoth (1998); Notestein et al. (1944); Lee (2001).
} 
expectancy will never lead to immortality. It is striking, however, that centenarians may become commonplace within the lifetimes of people alive today.

In all countries except the record holder, female life expectancy will be shorter than the best-practice level. Life expectancy could be estimated by forecasting the gap. The U.S. disadvantage varied from a decade in 1900 to less than a year in 1950 and about 5 years in 2000. If the trend in record life expectancy continues and if the U.S. disadvantage is between a year and a decade in 2070, then female life expectancy would be between 92.5 and 101.5, considerably higher than the U.S. Social Security Administration's forecast of 83.9.

An alternative method for forecasting life expectancy is to compute the average rapidity of improvement in age-specific death rates over many decades and then to use this information to project death rates over coming decades ${ }^{5}$ (Lee and Carter 1992; Alho 1998; Tuljapurkar et al. 2000; Wilmoth 1998; Olshansky et al. 2001; Lee 2001). In the early 1940s, when he was a student at Princeton University, the eminent demographer Ansley Coale developed and applied a version of this method (Notestein et al. 1944). Today vastly superior data resources are available ${ }^{6}$ and powerful, practicable methods have been developed to do more than Coale attempted (see e.g. Lee and Carter 1992; Alho 1998; Tuljapurkar et al. 2000). These methods use information about fluctuations in the speed of change in the past to estimate confidence bounds for the uncertainty enveloping life expectancy in the future. The official Japanese forecast, issued in 1997, for life expectancy (for males and females combined) in the year 2050 is 82.95 years (NIPSSR 1997). Projections based on the pattern of reductions in death rates in Japan since 1950 result in a life expectancy some 8 years longer, 90.91 years, with a $90 \%$ confidence range from 87.64 to 94.18 years (Tuljapurkar et al. 2000).

Progress in reducing mortality might be systematically slower than in the past. Officials could produce low life-expectancy scenarios to capture this eventuality. Then, however, they should also publish high scenarios that recognize that biomedical research may yield unprecedented increases in survival. Given the extraordinary linearity of the increase in best-practice life expectancy and given the ludicrous record of specious life-expectancy limits, the central forecast should be based on the long-term trend of sustained progress in reducing mortality.

\subsection{Continuing Belief in Looming Limits}

Faith in proximate longevity limits endures, sustained by ex cathedra pronouncements and mutual citations. In their quest to impose a cap on average longevity, students of mortality ignored essential research questions. Major changes in life expectancy hinge on improvements in survival at advanced ages, but comprehensive

\footnotetext{
${ }^{5}$ See footnote 4 above.

${ }^{6}$ See footnote 1 above.
} 
analysis of the remarkable reductions since the mid-twentieth century in death rates after age 80 first flourished in the 1990s (Kannisto et al. 1994; Kannisto 1996; Vaupel 1997; Wilmoth et al. 2000; Vaupel et al. 1998). Hypothesized biological barriers to longer lifespans also first received systematic attention (and refutation) a decade ago (Vaupel et al. 1998; Carey et al. 1992; Curtsinger et al. 1992; Wachter and Finch 1997; Carey and Judge 2001). The impact of continuing mortality improvements on life expectancy attracted empirical and theoretical attention in the late 1980s, with refined methods developed over the past decade (Lee and Carter 1992; Alho 1998; Tuljapurkar et al. 2000; Vaupel 1986; Vaupel and Canudas Romo 2000). It now appears plausible that life expectancy in several post-industrial countries may approach or exceed 90 by the middle of this century (Tuljapurkar et al. 2000; Wilmoth 1998) and that half the girls born today in countries such as France and Japan may become centenarians (Vaupel 1998, 1997).

If the expectation of life in developed countries were approaching an imminent maximum, then the pace of improvement in mortality in the countries with the highest life expectancies would be slower than the pace in countries with shorter life expectancies. There is, however, no correlation between the level of life expectancy and the pace of improvement (Kannisto et al. 1994; Wilmoth 1997). Indeed, in the current life-expectancy leader, Japan, death rates are falling exceptionally rapidly. Furthermore, as life expectancy rose over the course of the twentieth century, the pace of mortality improvement at older ages accelerated (Kannisto et al. 1994; Kannisto 1996; Vaupel 1997, Wilmoth et al. 2000; Wilmoth 1997). Even after age 100, death rates are falling (Kannisto 1996; Vaupel 1997; Wilmoth et al. 2000). Female life expectancy is higher than the male level in long-lived countries, but female life expectancy is increasingly somewhat more rapidly (Kannisto et al. 1994; Wilmoth 1997).

Olshansky et al. (2001) emphasize a theoretical barrier: "entropy in the life table means that small but equal incremental gains in life expectancy require progressively larger reductions in mortality.... Projections based on biodemographic principles that recognize the underlying biology within the life table would lead to more realistic forecasts of life expectancy that reflect the demographic reality of entropy in the life table." Entropy in the life table is merely the statistic

$$
\int s(a, t) \ln s(a, t) d a / \int s(a, t) d a,
$$

where $s(a, t)$ is the probability of surviving from birth to age $a$ at age-specific death rates prevailing at time $t$. Contrary to Olshansky et al.'s claim, in countries with long life expectancies a continuing rate of decline in age-specific death rates of $\mathrm{N}$ percent per year will increase life expectancy at birth by about $\mathrm{N}$ years per decade (Vaupel 1986; Vaupel and Canudas Romo 2000). Note that steady rates of change in mortality levels produce steady absolute increases in life expectancy: this relationship may underlie the linear trend of record life expectancy. In any case, valid biodemographic principles impose no insurmountable barriers to longer lives 
(Vaupel et al. 1998; Carey et al. 1992; Curtsinger et al. 1992; Wachter and Finch 1997; Carey and Judge 2001).

In sum, the past decade of mortality research has refuted the empirical misconceptions and purported theories that underlie the belief that the expectation of life cannot rise much further. In this article we have added a further line of cogent evidence. If life expectancy were close to its maximum, then the increase in the record expectation of life should be slowing. It is not. For 160 years, bestperformance life expectancy has steadily increased by a quarter of a year per year, an extraordinary constancy of human achievement.

\section{References}

Alho, J. (1998). A stochastic forecast of the population of Finland. Statistics Finland Reviews, 4(1). Helsinki: Tilastokeskus.

Bourgeois-Pichat, J. (1952). Essai sur la mortalité biologique de l'homme. Population, 7(3), 381-394.

Bourgeois-Pichat, J. (1978). Future outlook for mortality decline in the world. Population Bulletin of the United Nations, 11, 12-41.

Carey, J. R., \& Judge, D. S. (2001). Principles of biodemography with special reference to human longevity. Population: An English Selection, 13, 9-40.

Carey, J. R., Liedo, P., Orozco, D., \& Vaupel, J. W. (1992). Slowing of mortality rates at older ages in large medfly cohorts. Science, 258, 457-461.

Cruijsen, H., \& Eding, H. (2001). Latest national mortality forecasts in the European Union. In E. Tabeau, A. van den Berg Jeths, \& C. Heathcote (Eds.), Forecasting mortality in developed countries (pp. 227-245). Dordrecht: Kluwer Academic.

Curtsinger, J. W., Fukui, H. H., Townsend, D., \& Vaupel, J. W. (1992). Demography of genotypes: Failure of the limited life-span paradigm in Drosophila melanogaster. Science, 258, 462-463.

Demeny, P. (1984). A perspective on long-term population growth. Population and Development Review, 10(1), 103-126.

Dublin, L. I. (1928). Health and wealth. New York: Harper.

Dublin, L. I., \& Lotka, A. J. (1936). Length of life: A study of the life table. New York: Ronald Press.

Fogel, R. W., \& Costa, D. L. (1997). A theory of technophysio evolution, with some implications for forecasting population, health care costs, and pension costs. Demography, 34(1), 49-66.

Frejka, T. (1973). The future of population growth. New York: Wiley.

Frejka, T. (1981). Long-term prospects for world population growth. Population and Development Review, 7(3), 489-511.

Fries, J. F. (1980). Aging, natural death, and the compression of morbidity. New England Journal of Medicine, 303, 130-135.

Fries, J. F. (1990). Compression of morbidity: Near or Far? Milbank Quarterly, 67, 208-232.

Human Mortality Database. University of California, Berkeley (USA), and Max Planck Institute for Demographic Research (Germany). Available at: http://www.demog.berkeley.edu/wilmoth/ mortality

Kannisto, V. (1996). The advancing frontier of survival. Odense: Odense University Press.

Kannisto, V., Lauritsen, J., Thatcher, A. R., \& Vaupel, J. W. (1994). Reductions in mortality at advanced ages: Several decades of evidence from 27 countries. Population and Development Review, 20(4), 793-810. 
Keilman, N. (1997). Ex-post errors in official population forecasts in industrialized countries. Journal of Official Statistics, 13(3), 245-277.

Keyfitz, N., \& Flieger, W. (1968). World population: An analysis of vital data. Chicago: University of Chicago Press.

Lee, R. D. (2000). Long-term population Projections and the US social security system. Population and Development Review, 26(1), 137-143.

Lee, R. D. (2001). Predicting human longevity. Science, 292(5522), 1654-1655.

Lee, R. D., \& Carter, L. (1992). Modeling and forecasting the times series of U.S. mortality. Journal of the American Statistical Association, 419(87), 659-671.

Martin, L. G., \& Preston, S. H. (1994). Demography of aging. Washington, DC: National Academy Press.

NIPSSR (National Institute of Population and Social Security Research). (1997). Population projection of Japan, 1996-2050. Tokyo: NIPSSR.

Notestein, F., Taeuber, I. B., Kirk, D., Coale, A. J., \& Kiser, L. K. (1944). The future population of Europe and the Soviet Union (Vol. 5, pp. 183-189). Geneva: League of Nations.

Oeppen, J., \& Vaupel, J. W. (2002). Broken limits to life expectancy. Science, 296(5570), 1029-1031.

Olshansky, S. J., Carnes, B. A., \& Cassel, C. (1990). In search of methuselah: Estimating the upper limits to human longevity. Science, 250(4981), 634-640.

Olshansky, S. J., Carnes, B. A., \& Désesquelles, A. (2001). Prospects for human longevity. Science, 201(5508), 1491-1492.

Preston, S. H. (1974). Evaluation of postwar mortality projections in the United States, Canada, Australia, New Zealand. World Health Statistics Report, 27(1), 719-745.

Riley, J. (2001). Rising life expectancy: A global history. Cambridge: Cambridge University Press.

Siegel, J. S. (1980). Recent and prospective demographic trends for the elderly population and some implications for health care. In S. G. Haynes \& M. Feinlied (Eds.), Second conference on the epidemiology for aging (NIH Publ. No. 80-969) (pp. 17-82). Bethesda: US Department of Health and Human Services.

Tuljapurkar, S., Li, N., \& Boe, C. (2000). A universal pattern of mortality decline in the G7 countries. Nature, 405(June), 789-792.

United Nations. (1973). World population prospects as assessed in 1968. New York: UN.

United Nations. (1985). World population prospects as assessed in 1984. New York: UN.

United Nations. (1989). World population prospects 1988. New York: UN.

United Nations. (1999). World population prospects 1998. New York: UN.

United Nations. (2001). World population prospects 2000. New York: UN.

Vaupel, J. W. (1986). How change in age-specific mortality affects life expectancy. Population Studies, 40(1), 147-157.

Vaupel, J. W. (1997). The average French baby may live 95 or 100 years. In J. M. Robine et al. (Eds.), Longevity: To the limits and beyond (pp. 11-28). Berlin: Springer.

Vaupel, J. W. (1998). Demographic thinking. Science, 280(5366), 986.

Vaupel, J. W. (2000). Setting the stage: A generation of centenarians? The Washington Quarterly, 23(3), 197-200.

Vaupel, J. W., \& Canudas Romo, V. (2000). How mortality improvement increases population growth. In E. J. Docker et al. (Eds.), Optimization, dynamics, and economic analysis: Essays in honor of Gustav Feichtinger (pp. 345-352). Physica Verlag: Heidelberg/New York.

Vaupel, J. W., Carey, J. R., Christensen, K., Johnson, T. E., et al. (1998). Biodemographic trajectories of longevity. Science, 280, 855-860.

Wachter, K. W., \& Finch, C. E. (Eds.). (1997). Between zeus and the salmon: The biodemography of longevity. Washington, DC: National Academy Press.

Whelpton, P. K., Eldridge, H. T., \& Siegel, J. S. (1947). Forecasts of the population of the United States 1945-1975. Washington, DC: US. Bureau of the Census. 
Wilmoth, J. W. (1997). In search of limits. In K. W. Wachter \& C. E. Finch (Eds.), Between zeus and the salmon: The biodemography of longevity (pp. 38-64). Washington, DC: National Academy Press.

Wilmoth, J. R. (1998). The future of human longevity: A demographer's perspective. Science, 280 (5362), 395-397.

Wilmoth, J. R., Deegan, L. J., Lundstrom, J., \& Horiuchi, S. (2000). Increase of maximum life-span in Sweden, 1961-1999. Science, 289, 2366-2368.

Open Access This chapter is licensed under the terms of the Creative Commons Attribution 4.0 International License (http://creativecommons.org/licenses/by/4.0/), which permits use, sharing, adaptation, distribution and reproduction in any medium or format, as long as you give appropriate credit to the original author(s) and the source, provide a link to the Creative Commons license and indicate if changes were made.

The images or other third party material in this chapter are included in the chapter's Creative Commons license, unless indicated otherwise in a credit line to the material. If material is not included in the chapter's Creative Commons license and your intended use is not permitted by statutory regulation or exceeds the permitted use, you will need to obtain permission directly from the copyright holder. 